\title{
STABILITY ANALYSIS OF A TWT AGAINST THE REFLECTED SIGNAI.S USING A LARGE-SIGNAL MODEL
}

\author{
Vishnu Srivastava, SN Joshi and RG Carter* \\ Communication Tubes Group, MWT Div. \\ Central Electronics Engineering Research Institute, Pilani (India) 333031 \\ "Department of Engineering, University of Lancaster, Lancaster, U.K.
}

\begin{abstract}
A large signal model is used to analyze the stability of a high gain helix TWT against the reflected signals caused by mismatches at its input and output terminations. The stability of a section of the tube in presence of the reflected signals is determined by making a number of passes through the section for a very low drive power. A section is considered stable if the output power converges after 4 passes. If the output power goes on increasing or dues not converge then the section is defined as unstable. Results are presented for a $60 \mathrm{~W}$ helix TWT which is designed both in two-section and in three-section for small-signal gain more than $60 \mathrm{~dB}$. It is shown that the two-section TWT can be made stable with $10 \mathrm{~dB}$ return loss at the input and output terminations, only if the tip loss profile at the sever can be designed to have a return loss of more than $30 \mathrm{~dB}$. For the three-section tube, the return loss at the sever does not need to be greater than $20 \mathrm{~dB}$ for stable output performance.
\end{abstract}

\section{Introduction}

A helix TWT is a medium power microwave amplifier whose gain can be $60 \mathrm{~dB}$ or more. For such a high gain TWT, stability against reflected signals caused by mismatches at the input and output terminations is an important design aspect. It is known [1] that, for stability against the reflected signal, the small-signal gain of a one-section tube $\left(G_{s s}\right)$ should be less than the sum of the return loss at the input $\left(R_{\text {in }}\right)$ and output $\left(\mathrm{R}_{\text {out }}\right)$ terminations and the circuit loss of the section. Thus,

$$
\mathbf{G}_{\text {ss }}<\left(\mathbf{R}_{\text {in }}+\mathbf{R}_{\text {out }}+\text { Loss }\right) d B
$$

The return loss at the input and output terminations for a working helix TWT (with beam $\mathrm{ON}$ ) can be as high as $10 \mathrm{~dB}$. Therefore, the gain of a one-section helix TWT having circuit loss around $6 \mathrm{~dB}$ should not be more than $26 \mathrm{~dB}$ for stable performance. It is, therefore, necessary to design the helix slowwave circuit of a TWT having stable gain more than $60 \mathrm{~dB}$ either in two or three sections separated by severs (Figs. 1 and 2). The position of a sever is also an important design aspect and it should be optimized for maximum available saturated efficiency of the tube [2]. This can be achieved when the small-signal gain of the output section is not less than $27 \mathrm{~dB}$. Because of the requirement of high gain in the output section for maximum available saturated efficiency, its stability against the reflected signals caused by mismatches at the terminations was studied using a helix largesignal model [3-5].

\section{Approach of using large-signal model}

The effect of the reflected voltage component on the electron beam is determined by iterating the simulation of the interaction between the electron beam and the RF wave on the helix through the section of a tube. The large-signal model [3-5] simulates the multi-signal effects and includes the induced backward voltage components and the effect of the reflected voltages caused by mismatches at each end of a section. The measured values of the reflection at the input and output couplers are used but the reflection is set to $100 \%$ at sever because the helix is shorted to the body at this position. Reflected voltage component for the $\mathrm{n}^{\text {th }}$ signal at the output plane $\left(\mathrm{k}=\mathrm{k}_{2}\right)$ of a section moving in the backward direction is defined as follows: 
(i) at sever end of the input section:

$\mathrm{VBR}_{\mathrm{n}, \mathrm{k} 2}=\left(\mathrm{VF}_{\mathrm{n}, \mathrm{k} 2}\right)^{*}$

(ii) at coupler end of the output section:

$\mathbf{V B R}_{n, k 2}=\mathbf{R}_{\mathrm{n}, \text { out }}\left(\mathbf{V F}_{\mathrm{n}, \mathrm{k} 2}\right)^{*}$

where, $R_{n, \text { out }}$ is the voltage reflection coefficient for the $\mathrm{n}^{\text {th }}$ signal at the output coupler and $\left(\mathrm{VF}_{\mathrm{n}, \mathrm{k} 2}\right)^{*}$ is the complex conjugate of the forward voltage component of the $n^{\text {th }}$ signal at the last plane $\mathrm{k}_{2}$ of a section.

Similarly, the effect of a mismatch at the input end of a section is introduced. The reflected voltage component $\left(\mathrm{VFR}_{\mathrm{n}, \mathrm{k} 1}\right)$ at the input end $\left(\mathrm{k}=\mathrm{k}_{1}\right)$ moving in the forward direction is given as follows:

(i) at sever end of the output section:

$\mathbf{V F R}_{n, k 1}=\left(\mathrm{VB}_{\mathrm{n}, \mathrm{k} 1}\right)^{*}$

(ii) at coupler end of the input section:

$\mathbf{V F R}_{n, k 1}=R_{n, \text { in }}\left(\mathbf{V B}_{n, k 1}\right)^{*}$

where, $R_{n, i n}$ is the voltage reflection coefficient of the $n^{\text {th }}$ signal at the input coupler end and $\left(\mathrm{VB}_{\mathrm{n}, \mathrm{k} 1}\right)^{*}$ is the complex conjugate of the backward voltage component of the $n^{\text {th }}$ signal at the first plane $\left(k=k_{1}\right)$ of a section.

By including the effect of the reflected voltages in the above manner, it is possible to simulate the effect of the tip loss profiles at severs [6]. The reflected signal at the tip of the sever loss is determined by modeling the tube with large drive power and using very low beam current so that the gain is effectively zero. The ratio of the reflected power to the incident power at the tip of the sever loss determines the return loss at the sever. The stability of a section against reflections caused by mismatches at the terminations and against the backward voltage components can then be studied by making a number of passes through the section with normal beam current and very low drive power [6]. A section is considered stable if the output power converges after 4 passes. If the output power goes on increasing or does not converge then the section is defined as unstable. In practice it is desirable to achieve greater return loss than the minimum required for stability to reduce the amplitude of the gain ripple [7].

\section{Analysis of a high gain helix TWT}

The results for a $60 \mathrm{~W}$ output power, $60 \mathrm{~dB}$ gain helix TWT operating at a beam voltage of $3.0 \mathrm{kV}$ and beam current $75 \mathrm{~mA}$, are presented. This tube was designed in both two-section and three-section versions for maximum available saturated electronic efficiency with helix pitch and loss profiles as shown in Fig.1 and Fig.2, respectively. The return loss at the input and at the output terminations was taken to be $10 \mathrm{~dB}$. Length, shape and total loss of the sever loss are selected for achieving return loss much better than $30 \mathrm{~dB}$ at the tip of the sever loss. The length and loss of the tip loss profiles for the three-section TWT are reduced for achieving the comparable performances. TableI and Table-II given on the next page show respectively the computed performances at saturation of the two-section TWT and the three-section TWT over the frequency band of 3.60 to $4.20 \mathrm{GHz}$. These results were computed including the effect of the reflected signals.

Fig.3 compares the power profiles of the 2section and the 3-section TWT. In the 2-section TWT the output section is longer and it has small-signal gain of $33.50 \mathrm{~dB}$. It is found, in this case, that the output section is stable with a return loss at the output port of $10 \mathrm{~dB}$ when the return loss at the sever is greater than $30 \mathrm{~dB}$. Therefore, the loss profile of the tip loss is very critical to the stability of a two-section tube of gain $60 \mathrm{~dB}$. In the three-section TWT; the output section has small-signal gain of $26.5 \mathrm{~dB}$. It was found that the output section is stable, with the return loss at the output port of $10 \mathrm{~dB}$, when the return loss at the sever is greater than $20 \mathrm{~dB}$. Thus the profile of the tip loss is less critical in this case. The stability of the output section of the 2-section TWT can be improved against the higher reflections at the terminations by reducing its length but this reduces the saturated efficiency. For example, if the length of the output section is reduced by 
one magnet cell of length $5.30 \mathrm{~mm}$, this will reduce the maximum available saturated efficiency by $4 \%$ at $3.60 \mathrm{GHz}$.

\section{Conclusion}

A large-signal model has been used to study the stability of a high gain helix TWT against the reflected signals caused by mismatches at the terminations. The tube stuciied was a $60 \mathrm{~W}$ helix TWT designed for more than $60 \mathrm{~dB}$ gain both in 2-section and in 3-section versions. It was concluded that the tube can be made in two sections with return loss at the input and output terminations of $10 \mathrm{~dB}$, only if the tip loss profile at the sever can be designed to achieve a return loss greater than $30 \mathrm{~dB}$. For the three-section tube, the output section is stable, with return loss $10 \mathrm{~dB}$ at the output, if the return loss at the sever is greater thain $20 \mathrm{~dB}$. This makes it easier to achieve stability at the price of some loss in efficiency.

\section{Acknowledgement}

Thanks to ISRO, Bangalore for sponsoring the TWT project at CEERI, Pilani; to the Director, CEERI, for granting permission to present this paper in the conference; and to Prof. BN Basu of the Banaras Hindu University, Varanasi for helpful comments.

\section{Reỉerences}

[1] AS Gilmour Jr., 'Principles of traveling Wave Tubes', Artech House, Boston, 1994.

[2] V Srivastava \& RG Carter. 'Determination of Sever Positions in coupled-cavity TWTs', IEE Proc. H, Vol. 138, No.1, pp. 55-60, 1991.

[3] V Srivastava \& SN Joshi 'Improved nonlinear model for multi-signal analysis of helix TWTs, IEE Proc. H, Vol. 139, No.2, pp. 129-134, 1992.

[4] V Srivastava, 'Software package for the onedimensional nonlinear multi-signal analysis for helix TWTs (SUNRAY 1-D)', Copyright, CEERI-CSIR (India), 1992.

[5] V Srivastava \& RG Carter, '2.5-Dimensional large signal model of helix TWT', Technical Report MRG 93/3, Dept. of Engineering, University of Lancaster, UK Sept.1993.

[6] V Srivastava \& RG Carter, 'Improvements in the 2.5-Dimensional large signal model of helix TWT, Technical Report MRG 98/2, Dept. of Engineering, University of Lancaster, UK, June, 1998.

[7] S O Wallander, 'Reflexions and gain ripple in TWTs', IEEE Trans., Vol. ED-19, pp. 655-60, May 1972.

TABLE I: OUTPUT PERFORMANCE AT SATURATION FOR TWO-SECTION TUBE

\begin{tabular}{|c|c|c|c|c|c|}
\hline $\begin{array}{c}\text { Frequency } \\
(\mathrm{GHz})\end{array}$ & $\begin{array}{c}\text { Power } \\
(\mathrm{dBm})\end{array}$ & $\begin{array}{c}\text { Gain } \\
(\mathrm{dB})\end{array}$ & $\begin{array}{c}\text { Phase Shift } \\
(\mathrm{Deg} .)\end{array}$ & $\begin{array}{c}\text { Efficiency } \\
(\%)\end{array}$ & $\begin{array}{c}\text { Harmonics } \\
\text { Power }(\mathrm{dBm})\end{array}$ \\
\hline 3.6 & 48.76 & 53.19 & 23.82 & 33.41 & 31.61 \\
\hline 3.9 & 48.92 & 56.37 & 40.02 & 34.66 & 21.69 \\
\hline 4.2 & 48.55 & 58.55 & 55.56 & 31.85 & 26.57 \\
\hline
\end{tabular}

TABLE II: OUTPUT PERFORMANCE AT SATURATION FOR THREE-SECTION TUBE

\begin{tabular}{|c|c|c|c|c|c|}
\hline $\begin{array}{c}\text { Frequency } \\
(\mathrm{GHz})\end{array}$ & $\begin{array}{c}\text { Power } \\
(\mathrm{dBm})\end{array}$ & $\begin{array}{c}\text { Gain } \\
(\mathrm{dB})\end{array}$ & $\begin{array}{c}\text { Phase Shift } \\
(\mathrm{Deg})\end{array}$ & $\begin{array}{c}\text { Efficiency } \\
(\%)\end{array}$ & $\begin{array}{c}\text { Harmonics } \\
\text { Power }(\mathrm{dBm})\end{array}$ \\
\hline 3.6 & 48.36 & 53.59 & 20.50 & 30.47 & 32.94 \\
\hline 3.9 & 48.73 & 55.72 & 37.89 & 33.15 & 26.48 \\
\hline 4.2 & 48.59 & 57.13 & 52.36 & 32.13 & 20.17 \\
\hline
\end{tabular}



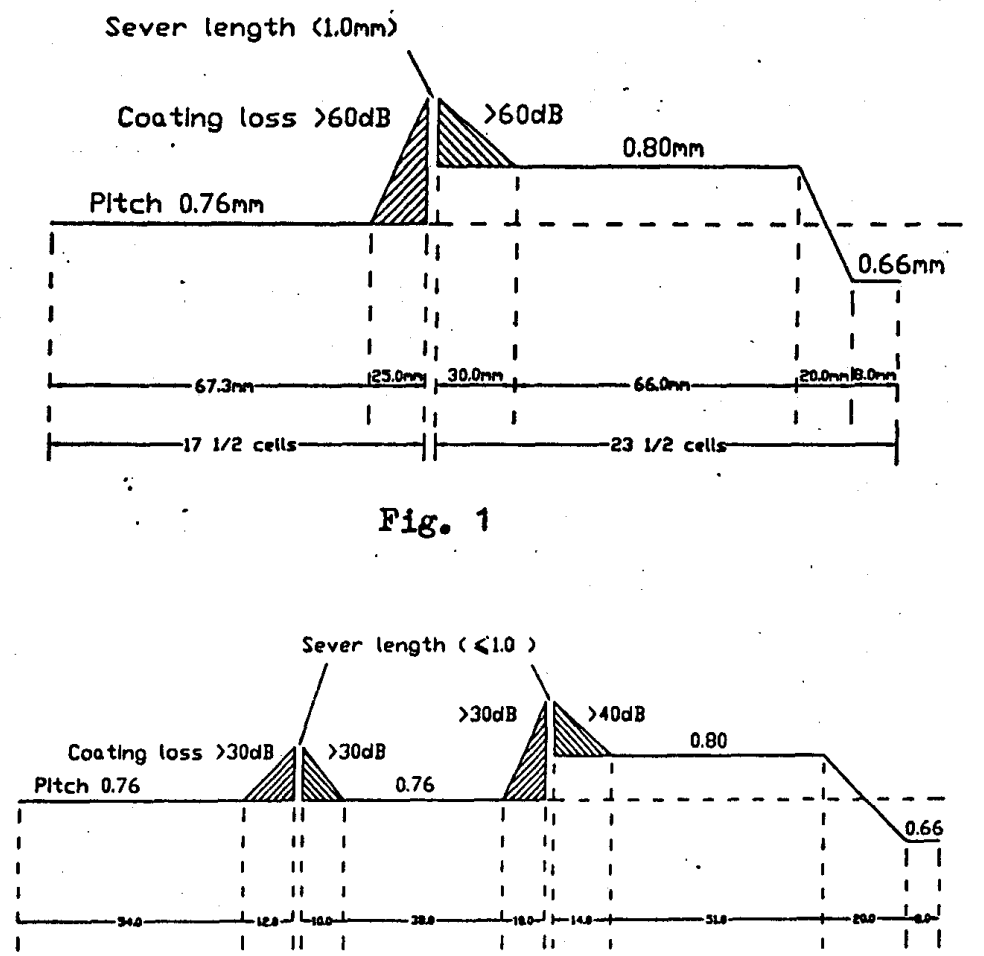

Fig. 2

All Dimensions are in mm

Ioss Profile and Pitch Profile in 2 - Section TWT (Fig.1) and 3 - Section TWT (Fig.2)

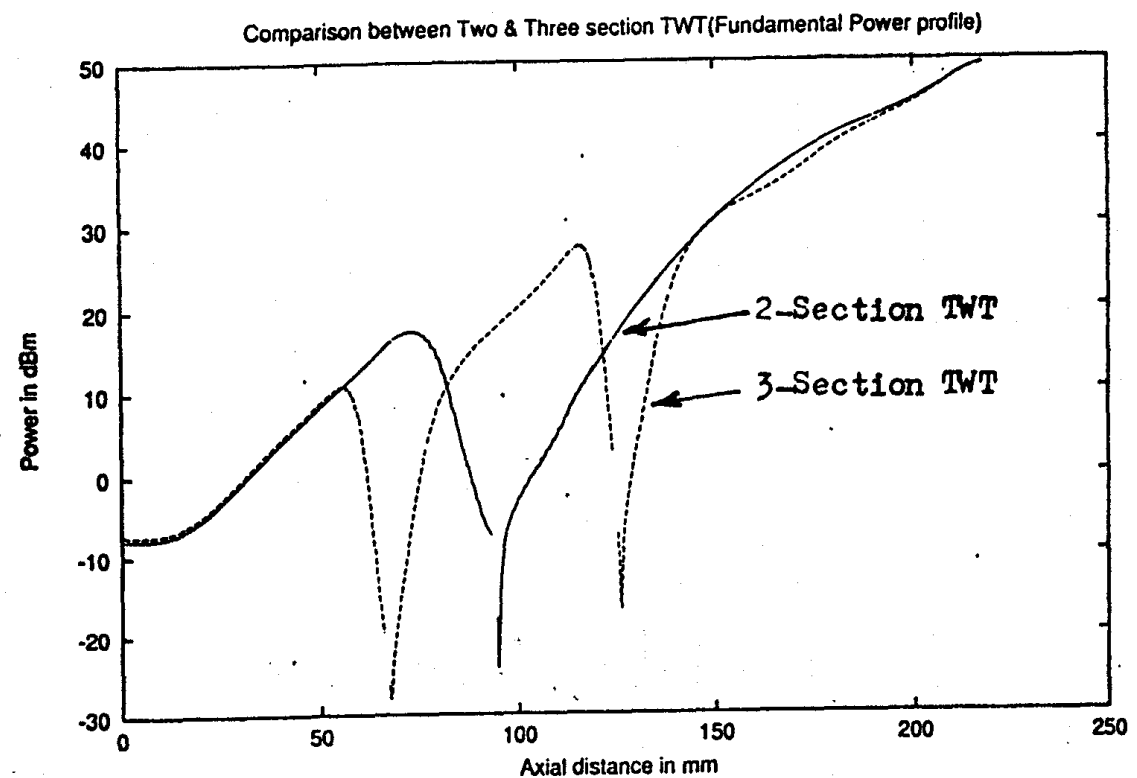

Fig. 3

$\cdot 83$ • 